\title{
Predaceous diving beetles (Coleoptera: Dytiscidae) may affect the success of amphibian conservation efforts
}

\author{
${ }^{1}$ Jose W. Valdez \\ ${ }^{1}$ Department of Bioscience - Kalø, Aarhus University, Grenåvej 14, 8410, Rønde, Denmark \\ Correspondence: ${ }^{1}$ jose.valdez@bios.au.dk
}

\begin{abstract}
The role of invertebrate predation in shaping vertebrate communities is often underestimated or overlooked, which has resulted in the lack of their recognition in conservation planning. This is evident with predaceous diving beetles (Coleoptera: Dytiscidae) which are often the top predator in many aquatic freshwater habitats. During weekly monitoring of a compensatory habitat reintroduction for an endangered frog species, a group of a dozen adult diving beetles were encountered attacking and quickly dismembering and consuming a tadpole. A single adult diving beetle was also discovered burrowing its head deep inside and consuming a tadpole approximately three to four times its size. Although Dytiscidae are known to occasionally consume vertebrates such as tadpoles, adults are typically considered scavengers, and this communal predatory behavior and feeding method have not been previously documented. Besides these interesting novel behaviors, these observations may have implications for amphibian conservation since management efforts are not typically concerned with naturally occurring ubiquitous threats such as those from small invertebrate predators, as it is rarely been observed in nature. However, this may be perhaps due to their ability to consume prey rapidly, especially if predating in groups. Although amphibian conservation plans expect some losses from natural predation, diving beetles may affect conservation efforts such as captive breeding and reintroductions with populations already on the threshold of extinction and where every individual critical to success.
\end{abstract}

Keywords. compensatory habitat, frog, invertebrate, predation, reintroduction, tadpoles

\section{Introduction}

In-situ and ex-situ conservation programs, including reintroductions to formerly occupied sites and translocations to compensatory habitats, have emerged as key management tools to mitigate the global decline of amphibians (Biega et al. 2017; Harding et al. 2016; Heatwole et al. 2018; Zippel et al. 2011). However, the success rate of such mitigation strategies has been fairly low, with few projects resulting in self-sustaining populations (Germano et al. 2009; Germano et al. 2015). Even initiatives that have been successful have required very large release numbers or a decade or more of intervention (Germano and Bishop 2009). Although studies have proposed many strategies to improve survival in managed populations (i.e., increased salinity to combat chytrid (Clulow et al. 2018) or removal of invasive predatory fish (KlopToker et al. 2018; Vredenburg 2004)), recent outcomes have been mixed (Harding et al. 2016). One possible 
reason may be because most conservation efforts are typically concerned with managing 'unnatural' threats such as habitat loss, disease, and invasive species; with little attention given to naturally occurring threats which may also severely affect managed species, particularly small and fragile populations where survival of every individual is critical.

The role of invertebrate predation in shaping vertebrate communities is often underestimated or entirely overlooked (Nordberg et al. 2018), which has resulted in a lack of their recognition in conservation planning. This is evident with predaceous diving beetles (Coleoptera: Dytiscidae) which are often the top predator in aquatic freshwater habitats around the world (Culler et al. 2014; Wellborn et al. 1996), yet are understudied as both an aquatic insect group and aquatic predator (Yee 2014). Although many aspects of their ecology and life history remaining relatively unknown, diving beetles are considered generalist predators which can cause trophic cascades due to their high feeding rates on zooplankton, aquatic invertebrates, and relatively small vertebrates (Cobbaert et al. 2010; Culler et al. 2014). The larvae are exclusively carnivorous and are commonly known as water tigers due to their voracious appetite, advanced chemical senses for detecting prey, and variety of hunting strategies, which can shift from sit-and-wait to active hunting based on habitat complexity (Michel et al. 2009; Yee 2010, 2014). They also possess large hollow curved mandibles which are used to pierce and inject digestive enzymes into their prey, before subsequently sucking and ingesting the liquefied mixture (Kehl 2014). This feeding behavior allows larvae to consume much larger prey, such as tadpoles (Pearman 1995; Tejedo 1993), fish (Culler et al. 2014), and even snakes (Drummond et al. 1981). Dytiscidae larvae are such effective predators that some tadpole undergo dytiscid-induced behavioral changes such as altered activity levels (Tejedo 1993), avoidance of areas where larvae are present (e.g., avoiding aquatic vegetation to prevent ambush attacks) (Rubbo et al. 2006; Smith et al. 2009), as well as a truncation of hatching time or decrease in tadpole size (Pearman 1995).

Although adult diving beetles are also known to occasionally predate on tadpoles (Cabrera-Guzmán et al. 2012) and fish (Culler et al. 2014; Melisi et al. 2016), they are mostly considered scavengers as they are perceived as less efficient and clumsy at capturing active prey, especially larger prey, due to their smaller body size and chewing parts that are more gape-limited compared to the larvae (Culler et al. 2014). However, recent evidence suggests that adults not only have the capability to predate on larger vertebrates but that their predatory behavior can have drastic effects on populations of endangered species (Bittel 2019). For example, conservation efforts to save the critically endangered Devils Hole pupfish saw limited success, until it was discovered that adult diving beetles were consuming fish twice their size and significantly hindering recruitment in the managed population (Bittel 2019; Heil 2018). Once the beetles were being actively removed, researchers who were recovering zero to one egg per month were now finding up to 100 
a week (Heil 2018). Although the predation capacity of adult beetles remains understudied, findings such as this allude to their potential impact on vertebrate populations within aquatic systems.

Predation of tadpoles by adult diving beetles was witnessed on 27 of January 2014 at 22:00 during nocturnal monitoring of a compensatory habitat reintroduction program of the green and golden bell frog (Litoria aurea) (for details see Valdez et al. (2019)). A group of a dozen adult diving beetles (unidentified) were encountered engulfing, attacking, and quickly dismembering a striped marsh frog (Limnodynastes peronii) tadpole (Figure 1), all in nearly a minute (Video 1: https://archive.org/details/2014012722.15.21). In a different area of the same pond, a single adult diving beetle was discovered consuming an L. peronii tadpole that was approximately three to four times its size (Figure 2; Video 2: https://archive.org/details/2014012722.16.53). In contrast to the typical feeding method recorded for adults, which are generally thought to tear their prey item into small pieces, this individual beetle had its head burrowed deep inside the tadpole in a manner similar to the feeding method of larvae, which pierce their prey and suck out its liquefied remains. To my knowledge, this communal predatory behavior and feeding method have not been previously described among diving beetles.

Besides the novelty of these behaviors, it was concerning how vicious and quickly the adult diving beetles consumed their much larger tadpole prey, especially considering that predation occurred within a managed compensatory habitat enclosed by predator-proof mesh which was designed to protect the managed sympatric species from large vertebrate predators. Although diving beetles were not observed predating on tadpoles of the reintroduced $L$. aurea species, it is possible that this interaction could at least partly explain the few remaining adults and lack of recruitment after only three years, despite being one of, if not the largest, amphibian reintroductions in Australia with 10,000 tadpoles originally released (Valdez et al. 2019). During the first year of weekly monitoring when tadpoles were first released, over 80 percent were found in ponds containing no beetles, with the largest densities consistently occurring in ponds with zero or a negligible number of beetles. Furthermore, although only a quarter of the naturally occurring ponds in the neighboring landscape were free of diving beetles they contained nearly half of all extant $L$. aurea tadpoles (Valdez et al. 2015). These findings suggest that the presence of adult diving beetles could have impacted the survival of $L$. aurea tadpoles to some extent before they had a chance to metamorphose out of the aquatic environment after reintroduction, thereby hampering the success of conservation efforts.

These observations may have implications for future amphibian conservation, given that current management efforts are typically not concerned with naturally occurring ubiquitous threats such as those from invertebrate predators. It is possible that predation by diving beetles has been ignored until now as it is rarely observed in nature, perhaps due their ability to consume prey rapidly, especially when working in 
together in a group. Their voracious appetite is well documented with experiments showing the capability of adults to consume at least nine tadpoles per day (Cabrera-Guzmán et al. 2012) and larvae able to consume dozens in a day (Kruse 1983). The impact diving beetle presence may have on conservation efforts can also be exacerbated in compensatory and restored habitats, since they are among the first macroinvertebrate predators to colonize new freshwater habitats (Bilton 2014). Another potential problem is that they have similar dispersal patterns to that of many amphibian species, dispersing from permanent to temporary ponds during the warmer breeding periods (Bilton 2014; Davy-Bowker 2002), with some diving beetles even depositing their eggs within amphibian egg clutches (J. Gould, pers. comm.). As temperatures continue to rise as a result of climate change, the impact diving beetles have on amphibian populations could become even more relevant to the success of conservation efforts, particularly if greater predation (Rall et al. 2010) and dispersal (Bilton 2014; Miguélez et al. 2008) rates result in poorer pre-metamorphic survival of more populations of endangered amphibians already on the edge.

With up to half of amphibian species threatened with extinction (IUCN 2018), all possible threats which may negatively impact conservation success must be identified. While invertebrate predation on vertebrates is largely ignored and underestimated, recent evidence suggests it may be more common with larger impacts on vertebrate populations than previously thought (Nordberg et al. 2018; Rudolf von May et al. 2019). Although amphibian conservation plans typically expect some losses from natural predation, diving beetles may seriously hamper efforts, particularly for populations already on the threshold of extinction where every individual is critical to prevent further declines. Despite representing the top predator and the most diverse or abundant Coleoptera taxon in numerous freshwater aquatic systems, many aspects of the ecology of predaceous diving beetles remain unknown (Yee 2014). However, the evidence presented here suggests that diving beetles may be significant predators of tadpoles even those much larger species, and their effect on amphibian populations, specifically tadpoles, should not be ignored. Further research should be conducted to quantify their impact on amphibian populations, breeding, and the success of amphibian conservation plans.

\section{Acknowledgements}

I wish to thank John Gould for his time providing constructive feedback and inspiration.

\section{References}

Biega A, Greenberg DA, Mooers AO, Jones OR, Martin TE. 2017. Global representation of threatened amphibians ex situ is bolstered by non-traditional institutions, but gaps remain. Animal Conservation 20(2): 113-119. doi:10.1111/acv.12297 
Bilton DT. 2014. Dispersal in Dytiscidae Pp. 387-407 In: Ecology, Systematics, and the Natural History of Predaceous Diving Beetles (Coleoptera: Dytiscidae). Editors, Yee DA. Dordrecht, Springer Netherlands.

Bittel J. (2019). Brutal beetles kept world's rarest fish from breeding — until now. Available: https://www.nationalgeographic.com/animals/2019/03/endangered-devils-hole-pupfish-breedingbreakthrough [Accessed: 05 March 2019].

Cabrera-Guzmán E, Crossland MR, Shine R. 2012. Predation on the eggs and larvae of invasive cane toads (Rhinella marina) by native aquatic invertebrates in tropical Australia. Biological Conservation 153: 1-9. doi:https://doi.org/10.1016/j.biocon.2012.04.012

Clulow S, Gould J, James H, Stockwell M, Clulow J, Mahony M. 2018. Elevated salinity blocks pathogen transmission and improves host survival from the global amphibian chytrid pandemic: Implications for translocations. Journal of Applied Ecology 55(2): 830-840. doi:doi:10.1111/1365-2664.13030

Cobbaert D, Bayley SE, Greter J-L. 2010. Effects of a top invertebrate predator (Dytiscus alaskanus; Coleoptera: Dytiscidae) on fishless pond ecosystems. Hydrobiologia 644(1): 103-114.

Culler LE, Ohba S, Crumrine P. 2014. Predator-prey interactions of dytiscids Pp. 363-386 In: Ecology, Systematics, and the Natural History of Predaceous Diving Beetles (Coleoptera: Dytiscidae). Editors, Yee DA. Dordrecht, Springer Netherlands.

Davy-Bowker J. 2002. A mark and recapture study of water beetles (Coleoptera: Dytiscidae) in a group of semi-permanent and temporary ponds. Aquatic Ecology 36(3): 435-446. doi:10.1023/a:1016550127986

Drummond H, Wolfe GW. 1981. An observation of a diving beetle larva (Insecta: Coleoptera: Dytiscidae) attacking and killing a garter snake, Thamnophis elegans (Reptilia: Serpentes: Colubridae). The Coleopterists Bulletin 35(1): 121-124.

Germano JM, Bishop PJ. 2009. Suitability of amphibians and reptiles for translocation. Conservation Biology 23(1): 7-15.

Germano JM, Field KJ, Griffiths RA, Clulow S, Foster J, Harding G, Swaisgood RR. 2015. Mitigationdriven translocations: are we moving wildlife in the right direction? Frontiers in Ecology and the Environment 13(2): 100-105. doi:doi:10.1890/140137

Harding G, Griffiths RA, Pavajeau L. 2016. Developments in amphibian captive breeding and reintroduction programs. Conservation Biology 30(2): 340-349. doi:doi:10.1111/cobi.12612

Heatwole H, Rowley J. 2018. Status of Conservation and Decline of Amphibians: Australia, New Zealand, and Pacific Islands. Victoria, Australia, CSIRO Publishing.

Heil J. (2018, July 12, 2018). From zero to 40. Available: https://www.fws.gov/cno/newsroom/Highlights/2018/zero_to_40 [Accessed: 15 March 2019].

IUCN. (2018). The IUCN Red List of Threatened Species. Available: http://www.iucnredlist [Accessed: 13 March 2019].

Kehl S. 2014. Morphology, anatomy, and physiological aspects of dytiscids Pp. 173-198 In: Ecology, Systematics, and the Natural History of Predaceous Diving Beetles (Coleoptera: Dytiscidae). Editors, Yee DA. Dordrecht, Springer Netherlands.

Klop-Toker K, Valdez J, Stockwell M, Clulow S, Clulow J, Mahony M. 2018. Community level impacts of invasive mosquitofish may exacerbate the impact to a threatened amphibian. Austral ecology 43(2): 213-224.

Kruse KC. 1983. Optimal foraging by predaceous diving beetle larvae on toad tadpoles. Oecologia 58(3): 383-388.

Melisi CJ, Piorkowski MD. 2016. Predation of a pupfish by a fishing spider subsequently stolen by a diving beetle. The Southwestern Naturalist 61(2): 135-137.

Michel MJ, Adams MM. 2009. Differential effects of structural complexity on predator foraging behavior. Behavioral Ecology 20(2): 313-317. 
Miguélez D, Valladares LF. 2008. Seasonal dispersal of water beetles (Coleoptera) in an agricultural landscape: a study using Moericke traps in northwest Spain. Annales de la Société entomologique de France (N.S.) 44(3): 317-326. doi:10.1080/00379271.2008.10697570

Nordberg EJ, Edwards L, Schwarzkopf L. 2018. Terrestrial invertebrates: An underestimated predator guild for small vertebrate groups. Food Webs 15: e00080. doi:https://doi.org/10.1016/j.fooweb.2018.e00080

Pearman PB. 1995. Effects of pond size and consequent predator density on two species of tadpoles. Oecologia 102(1): 1-8.

Rall BC, Vucic-Pestic O, Ehnes RB, Emmerson M, Brose U. 2010. Temperature, predator-prey interaction strength and population stability. Global Change Biology 16(8): 2145-2157.

Rubbo M, Mirza R, Belden L, Falkenbach J, Storrs S, Kiesecker J. 2006. Evaluating a predator-prey interaction in the field: the interaction between beetle larvae (predator) and tadpoles (prey). Journal of Zoology 269(1): 1-5.

Rudolf von May, Emanuele Biggi, Heidy Cárdenas, M. Isabel Diaz, Consuelo Alarcón, Valia Herrera, Roy Santa-Cruz, Francesco Tomasinelli, Erin P. Westeen, Ciara M. Sánchez-Paredes, Joanna G. Larson, Pascal O. Title, Maggie R. Grundler, Michael C. Grundler, Alison R. Davis Rabosky, Rabosky DL. 2019. Ecological interactions between arthropods and small vertebrates in a lowland Amazon rainforest. Amphibian \& Reptile Conservation 13(1): 65-77 (e169).

Smith GR, Awan AR. 2009. The roles of predator identity and group size in the antipredator responses of american toad (Bufo americanus) and bullfrog (Rana catesbeiana) tadpoles. Behaviour 146(2): 225-243.

Tejedo M. 1993. Size-dependent vulnerability and behavioral responses of tadpoles of two anuran species to beetle larvae predators. Herpetologica 49(3): 287-294.

Valdez JW, Klop-Toker K, Stockwell MP, Fardell L, Clulow S, Clulow J, Mahony MJ. 2019. Informing compensatory habitat creation with experimental trials: a 3-year study of a threatened amphibian. Oryx 53(2): 310-320. doi:10.1017/S0030605317000394

Valdez JW, Stockwell MP, Klop-Toker K, Clulow S, Clulow J, Mahony MJ. 2015. Factors driving the distribution of an endangered amphibian toward an industrial landscape in Australia. Biological Conservation 191: 520-528.

Vredenburg VT. 2004. Reversing introduced species effects: experimental removal of introduced fish leads to rapid recovery of a declining frog. Proceedings of the National Academy of Sciences 101(20): 7646-7650.

Wellborn GA, Skelly DK, Werner EE. 1996. Mechanisms creating community structure across a freshwater habitat gradient. Annual review of ecology and systematics 27(1): 337-363.

Yee DA. 2010. Behavior and aquatic plants as factors affecting predation by three species of larval predaceous diving beetles (Coleoptera: Dytiscidae). Hydrobiologia 637(1): 33-43.

Yee DA. 2014. Ecology, Systematics, and the Natural History of Predaceous Diving Beetles (Coleoptera: Dytiscidae). Dordrecht, Springer Netherlands.

Zippel K, Johnson K, Gagliardo R, Gibson R, McFadden M, Browne R, Martinez C, Townsend E. 2011. The Amphibian Ark: a global community for ex situ conservation of amphibians. Herpetological Conservation and Biology 6(3): 340-352. 

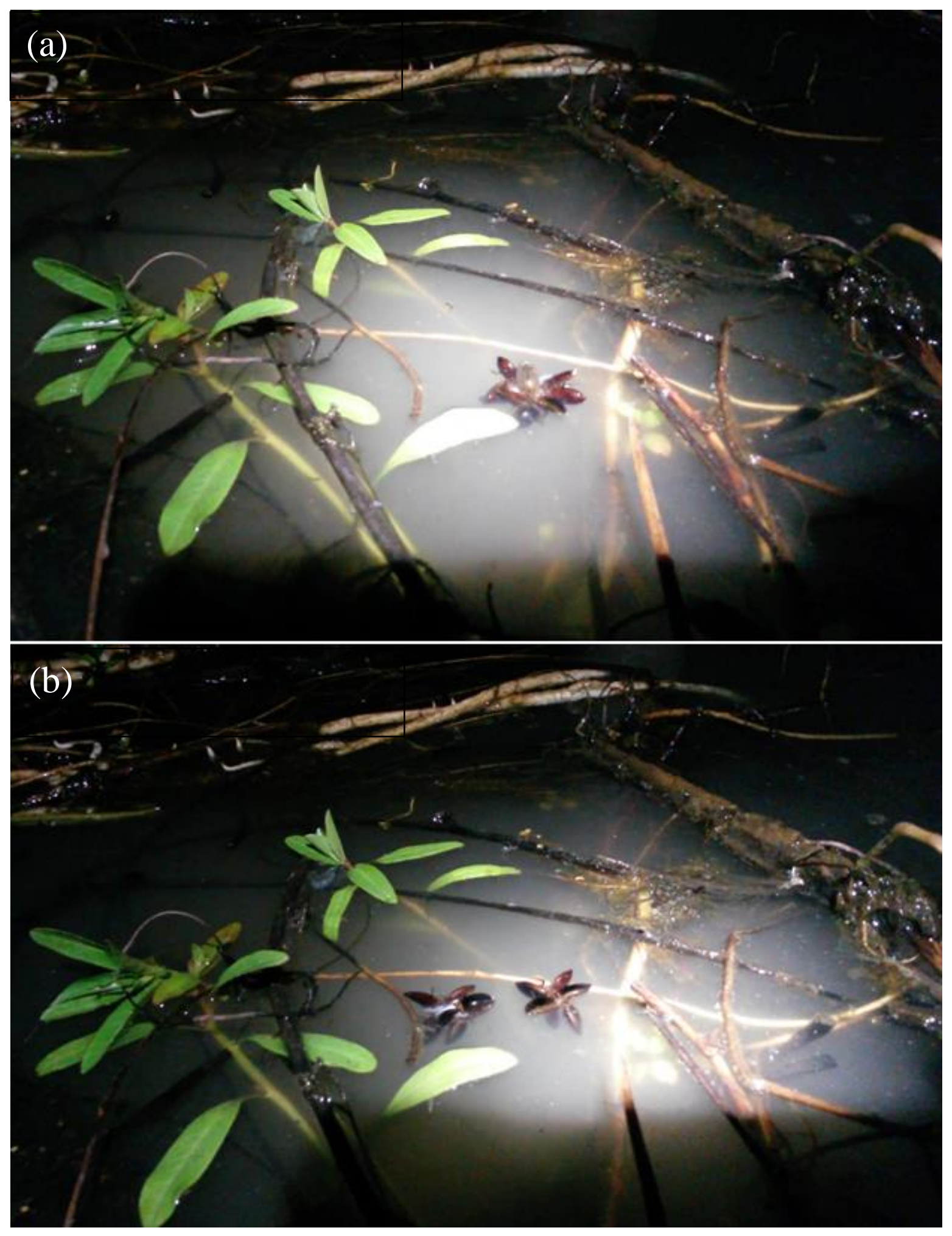

Figure 1. A group of approximately a dozen adult diving beetles (a) attacking and (b) dismembering a striped marsh frog (Limnodynastes peronii) tadpole in a managed pond in Newcastle, New South Wales, Australia. 


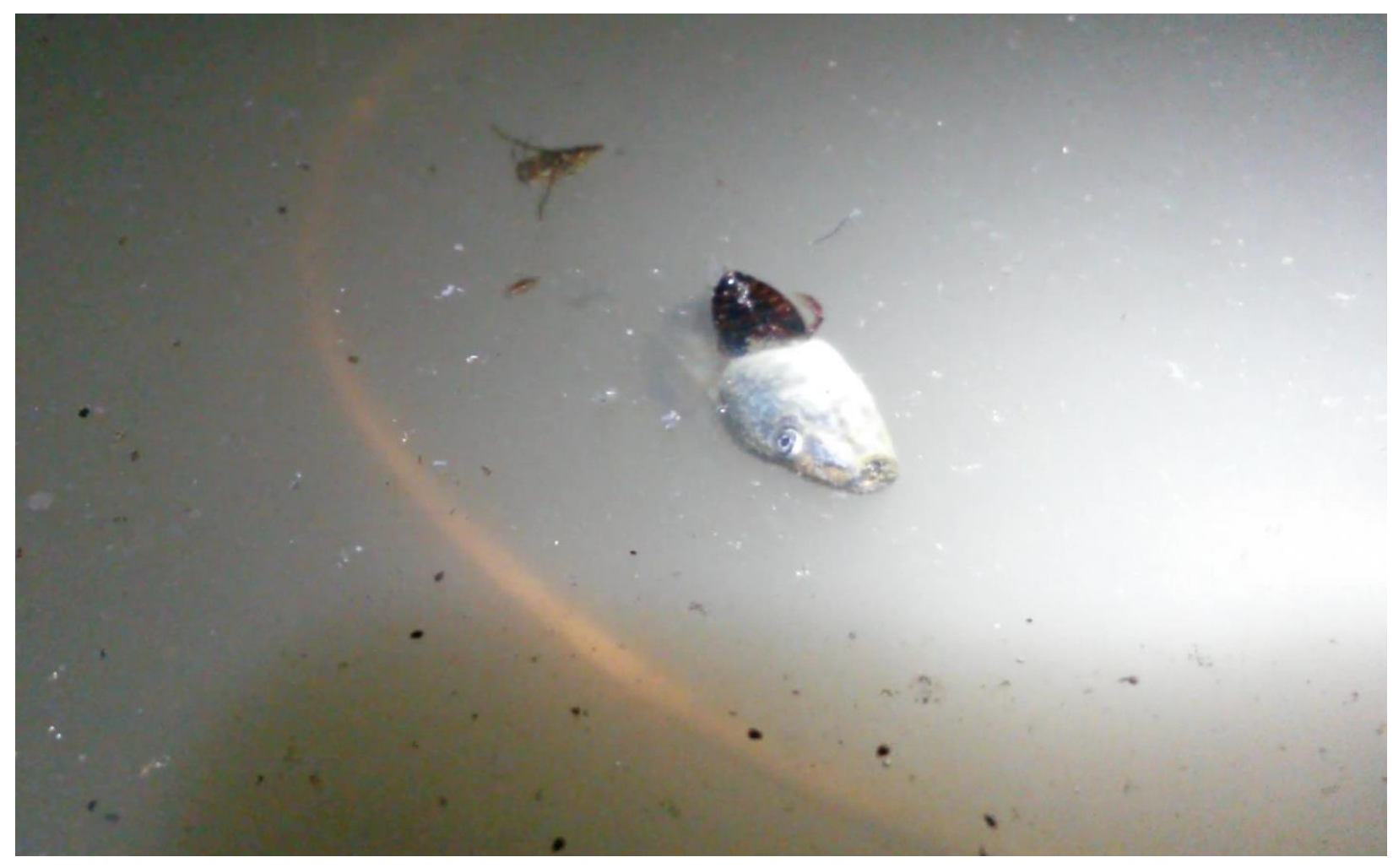

Figure 2. An adult diving beetle consuming a striped marsh frog (Limnodynastes peronii) tadpole with its head burrowed inside its abdomen in a managed pond in Newcastle, New South Wales, Australia. 